\title{
Knowledge and Attitude of Men towards Factors influencing Childhood Mortality in a Semi-Urban Community in Northwestern Nigeria
}

Ibrahim $M J^{1}$, Sani $Z M^{2}$, Olorukooba $A A^{2}$, Usman $N O^{1}$, Ahmad $A I^{1}$, MohammedIdris $Z K^{1}$

${ }^{1}$ Department of Community Medicine, Kaduna State University, Kaduna

${ }^{2}$ Department of Community Medicine, Ahmadu Bello University Zaria

Keywords

Childhood

mortality;

Child health;

Risk factors;

Male

involvement;

Zaria

\section{ABSTRACT}

Background: In spite of concerted global efforts to reduce childhood mortality, countries in Sub-Saharan Africa are still being plagued with incomparably high mortality rates; thereby contributing majorly to the global burden. These deaths occur from causes which are preventable. Men play a pivotal role in sustained efforts to reduce childhood mortality, however, they are usually overlooked in favour of the mothers. The study aimed to assess the knowledge and attitude of men towards factors influencing childhood mortality in a semi-urban community, North-Western Nigeria.

Methods: A descriptive cross-sectional study was conducted using structured interviewer-administered questionnaire. A total of 174 married men were sampled using a multistage sampling technique. Data collected were analysed using the IBM SPSS version 21. Results were presented in tables and bar charts. The level of statistical significance was set at $\mathrm{p}<0.05$.

Results: The mean age $( \pm \mathrm{SD})$ of the respondents was $38( \pm 11.2)$ years. One hundred and ten $(64.7 \%)$ of the respondents had lost a child under the age of five years. Majority $142(83.5 \%)$ of the respondents had poor knowledge of risk factors influencing childhood mortality and $141(82.9 \%)$ of the respondents had a positive attitude towards prevention of childhood mortality.

Conclusion: The study has highlighted the need for increased male involvement in child health issues. Interventions such as health education and community mobilization that aims to educate men on risk factors and danger signs associated with poor childhood health outcomes should be carried out in this area.

Correspondence to: Dr Ibrahim Mohammed Jimoh Department of Community Medicine, College of Medicine, Kaduna State University. Email: drjim20032000@yahoo.com Phone number: 08037871427

\section{INTRODUCTION}

Childhood mortality remains a public health issue of global proportions. There have been concerted global efforts to reduce childhood mortality, however, progress has mainly been achieved in the developed world. SubSaharan Africa still contributes majorly to the global burden. ${ }^{1}$ Globally, there were 5.3 million under-five deaths with Sub-Saharan Africa accounting for about half of those 
deaths. ${ }^{2}$ However, most of these deaths are from causes which are to a large extent preventable. Globally, India, Nigeria, Democratic Republic of Congo, Pakistan and China collectively accounted for half of the total number of under-five deaths. Children in sub-Saharan Africa are 15 times more likely to die before the age of five than children in developed countries. ${ }^{2}$ In 2018, the under-five mortality rate, infant mortality rate and neonatal mortality rate in Nigeria were 117 per 1000; 67 per 1000 and 39 per 1000 respectively. ${ }^{3}$ The United Nations Inter-Agency Group for Child Mortality Estimation (UNIGME) 2020 report showed that, in Nigeria, around 700,000 children died before their fifth birthday; $60 \%$ of these deaths were due to the following conditions: malaria (20\%), pneumonia $(17 \%)$, prematurity $(12 \%)$ and diarrhoea $(11 \%)$, and about $45 \%$ of all child deaths are linked to malnutrition. ${ }^{4,5}$

Maternal factors like the mother's age at first marriage, marital status, parity, health-seeking behavior, use of contraception, breastfeeding, birth interval and educational status are some maternal factors have been found to have strong associations with childhood mortality. ${ }^{6,7}$ It is widely accepted that the topic of maternal and child health should be one of great importance to men and women who have a shared interest in preventing maternal and childhood mortality. However, several barriers have been identified to men's involvement in child health. These include gender stereotyping, lack of a definitive role for men in maternal and child health, time constraints, health facility environment and women's reservations about men's involvement. 8,9 Studies have shown that men (especially in resource poor settings) have poor knowledge on child health as well as the basic preventive measures of common causes of childhood mortality. 10,11,12 A study among men in Ekiti State showed that almost half of the respondents had a negative attitude towards childhood immunisation which is one of the major preventive measure against the common childhood killer diseases. ${ }^{13}$

Child mortality is still a major scourge in Nigeria especially in the north western geopolitical zone which has the highest rate (with the rural areas being more hard-hit than urban areas). ${ }^{14}$ However, there is a dearth of information on the role of men in child health especially in the aforementioned region. This study aimed to determine the knowledge and attitude of men towards factors influencing child mortality in Magume Community in Kaduna State.

\section{METHODOLOGY}

\section{Study Area}

Magume is a semi-urban community located in the outskirts of Zaria City, the ancient town. It is one of the four communities under Tukur-Tukur ward of Zaria Local Government Authority (LGA) of Kaduna State. There are 13 wards in Zaria LGA. Magume has an estimated population of 4007 from the 2006 national census with a projected population of 5092. Magume community has the annex campus of Nuhu 
Bamali Polytechnic and is also in close proximity to the famous Barewa College. The main occupation is petty trading and civil service. There is only one primary school and a market in the area. The Ahmadu Bello University Teaching Hospital, is situated about two kilometres from the community. The Hausas constitute the major ethnic group in the area. Others include; Yoruba, Nupe, and Kataf. The inhabitants are predominantly muslims. There are two health facilities in the community and a few patent medicine stores. First is the primary healthcare centre that serves the community while the second healthcare delivery centre is a private hospital. Services rendered include antenatal care, surgery, medical consultations for adult and paediatric patients as well as laboratory investigations.

\section{Study Design}

A descriptive, cross-sectional communitybased study was carried out from June to September 2017, with the study population being married men aged 18 years and above. All male residents of Magume community who have been married for at least a year were included in the study while male residents who are temporarily residing in the community were excluded.

\section{Sample Size Determination}

Sample size was calculated using the Cochran's formula for cross-sectional studies when the outcome variable is a proportion. ${ }^{15}$ An absolute precision of $5 \%$ as well as a standard normal deviate at a confidence level of $95 \%$ corresponding to
1.96 was used in the computation. A prevalence of men with knowledge $(82.4 \%)$ from a previous study was inserted into the formula for calculating single proportion. ${ }^{12}$ Finite population correction as well as adjustment for non-response of $10 \%$ was applied. ${ }^{15,16}$ A minimum sample size of 174 respondents was finally achieved for the study.

\section{Sampling Technique}

Multistage sampling technique was applied in this study.

Stage 1: One ward, Tukur-Tukur was selected out of the 13 wards in Zaria LGA using simple random sampling method by balloting.

Stage 2: Magume community was selected out of the four communities that make up Tukur-Tukur ward using simple random sampling method.

Stage 3: House numbering and household listing was done from three out of the seven streets in the community, and a register of all households in each street was developed and used as sampling frame. After which 174 households out of 534 were selected using systematic sampling technique.

Stage 4: One eligible male respondent was selected from each of the selected households using simple random sampling by balloting.

\section{Data collection tool and procedure}

The tool for data collection was pretested structured interviewer-administered questionnaire. The questionnaire was drafted after a review of the literature on knowledge and attitude of men toward risk factors 
influencing maternal and child mortality. 6,7,9,10,20,23 The data collection was carried out by the researcher and four trained research assistants who were final year medical students of Ahmadu Bello University Zaria. The researcher supervised the overall data collection process and checked the filled questionnaires for consistency and completeness. The questionnaire comprised of three sections that sought information on sociodemographic profile of the respondents, knowledge of the causes and risk factors of child mortality, attitude towards the aforementioned risk factors. The knowledge of respondents on causes and risk factors of childhood death was assessed using 26 questions from the questionnaire. Each correct response to the question scored one mark while incorrect response scored zero. The respondent's cumulative scores on knowledge over the total were converted to percentage and graded. Those who scored above $70 \%$ were categorised as having good knowledge while those that scored between $50 \%$ and $70 \%$ were categorised as having fair knowledge and those who scored below $50 \%$ were categorised as having poor knowledge. ${ }^{17}$ The attitude of the respondents towards prevention of childhood death was assessed using six questions. The attitude was assessed using a 3-point Likert scale. Each question had scores ranging from 0 through 2 , that is, from the least favourable to the most favourable attitude score. The respondent's cumulative scores on attitude over total were converted to percentage and graded as follows: attitude of respondents was graded positive if they scored $50 \%$ or more while a negative attitude was graded as a score of less than $50 \% .18$

\section{Data analysis}

Data collected were coded, entered into the computer and analysed using Statistical Package for Social Sciences (SPSS, IBM Corporation USA) software version 21 . Results were arranged and presented in tables, bar charts, or pie charts. Univariate analysis using frequencies, proportions, means and standard deviations were used to represent single variables as appropriate. Bivariate analysis was carried out using Chi-square or Fisher's exact test to determine the association between independent variables (like socio-demographic characteristics) and dependent variables (like knowledge and attitude). Statistical significance was set at $\mathrm{p}<0.05$.

\section{Ethical consideration}

Approval to carry out this study was obtained from the Research and Ethics Committee of Ahmadu Bello University Teaching Hospital, Zaria. Permission to conduct the study was also sought from the Zaria Local Government Authority and the ward head. The study participants were informed about the purpose of the study and were also informed that they could voluntarily withdraw from the study at any time. Written informed consent was obtained from all the participants before the questionnaires were administered to them. Respondents were assured of confidentiality and the data obtained were stored in a 
password protected computer that was only accessible to researchers.

\section{RESULTS}

A total of 174 questionnaires were administered to the respondents out of which 170 were completely filled, returned and analysed after validation, giving a response rate of $98.0 \%$. One hundred and twelve $(65.9 \%)$ of the respondents were within 20-39 years with mean age $( \pm S D)$ of $38( \pm 11.2)$ years. Islam was the predominant religion $138(81.2 \%)$ of the respondents. Hausa ethnic group constituted 125 (73.6\%) of the respondents. About two-thirds 110 $(64.7 \%)$ of the respondents were married in a monogamous setting while the rest were in polygamous union. Half $85(50.0 \%)$ of the respondents had tertiary education. Above a third $65(38.2 \%)$ of the respondents were civil servants. Majority 110 (64.7\%) of the respondents had history of under-five deaths while 60 (35.3\%) never had underfive deaths (Table 1). Diarrhoea and measles were the commonest causes of childhood deaths as identified by $146(85.7 \%)$ of the respondents. Malnutrition was the least identified cause of child death by 108 $(63.7 \%)$ of the respondents (Figure 1).

The most commonly identified maternal factors influencing childhood mortality were poor health seeking behaviour 132 (78.1\%), lack of education 128 (75.7\%) and poverty 112 (66.3\%). Lack of breastfeeding 124 (73.4\%) and immunization 102 (60.4\%) were the commonest child factors recognized by the respondents. Unhygienic water source
157 (92.9\%), poor sanitation 142 (84.0\%) and poverty $133(78.7 \%)$ were the household/community factors associated with childhood mortality (Table 2). Most of the respondents $142 \quad(83.5 \%)$ obtained scores which fall into the category of poor knowledge while only $17(10.0 \%)$ of the respondents had good knowledge of childhood mortality risk factors (Table 2).

Majority of the respondents in each age group, 20 to 29 years 40 (78.4\%), 30 to 39 years 51 (83.6\%) had poor knowledge of the risk factors for childhood mortality, however, this was not statistically significant, $p<0.863$. All the respondents with formal education, 122 (100.0\%) compared to $12(44.4 \%)$ and $8(38.1 \%)$ with no education and Quranic education, respectively had poor knowledge of childhood mortality risk factors. This was statistically significant, $\mathrm{p}=0.001$. A high proportion of civil servants $59(90.8 \%)$ and traders 49 (97.9\%) had poor knowledge compared to those who engaged in farming $22(51.2 \%)$ and this was statistically significant, $\mathrm{p}=0.001$ (Table 3 ).

Half 85 (50.0\%) of the respondents believed that childhood deaths are preventable. Above half 95 (55.9\%) of the respondents disagreed that family planning could reduce the burden of childhood deaths (Table 4). Overall 141 (82.9\%) of respondents had positive attitude while only 29 (17.1\%) had negative attitude towards childhood mortality risk factors. 
Table 1: Socio-demographic characteristics of respondents

\begin{tabular}{|c|c|c|}
\hline Variable & $\begin{array}{l}\text { Frequency } \\
(\mathbf{n}=170)\end{array}$ & Percent \\
\hline \multicolumn{3}{|l|}{ Age (years) } \\
\hline $20-29$ & 51 & 30.0 \\
\hline $30-39$ & 61 & 35.9 \\
\hline $40-49$ & 34 & 20.0 \\
\hline $50-59$ & 16 & 9.4 \\
\hline $60-69$ & 8 & 4.7 \\
\hline \multicolumn{3}{|c|}{ Mean age (years) $38( \pm 11.2)$} \\
\hline \multicolumn{3}{|l|}{ Religion } \\
\hline Islam & 138 & 81.2 \\
\hline Christianity & 32 & 18.8 \\
\hline \multicolumn{3}{|l|}{ Tribe } \\
\hline Hausa & 125 & 73.6 \\
\hline Fulani & 26 & 15.3 \\
\hline Yoruba & 6 & 3.5 \\
\hline Igbo & 8 & 4.7 \\
\hline Others & 5 & 2.9 \\
\hline \multicolumn{3}{|c|}{ Highest level of education } \\
\hline None & 27 & 15.8 \\
\hline Quranic & 21 & 12.4 \\
\hline Primary & 16 & 9.4 \\
\hline Secondary & 21 & 12.4 \\
\hline Tertiary & 85 & 50.0 \\
\hline \multicolumn{3}{|l|}{ Occupation } \\
\hline Civil servant & 65 & 38.2 \\
\hline Trader/Businessman & 47 & 27.7 \\
\hline Farmer & 43 & 25.3 \\
\hline Others & 15 & 8.8 \\
\hline \multicolumn{3}{|l|}{ Number of wives } \\
\hline One & 110 & 64.7 \\
\hline Two & 46 & 27.1 \\
\hline Three & 9 & 5.3 \\
\hline Four & 5 & 2.9 \\
\hline \multicolumn{3}{|c|}{ History of under-five death } \\
\hline Yes & 110 & 64.7 \\
\hline No & 60 & 35.3 \\
\hline
\end{tabular}

Majority of the respondents in each age group; the 20 to 29 years, 39 (76.5\%), 30 to 39 years $51(83.6 \%)$ had a positive attitude, however, this was not statistically significant, $\mathrm{p}=0.413$. All the respondents with formal education 122 (100.0\%) had a positive attitude towards prevention of childhood mortality compared to those with no education 16 (59.3\%) or with Quranic education 13 (61.9\%) who had a negative attitude and the difference was statistically significant, $p=0.001$. A high proportion of the respondents who were civil servants 53 (81.5\%), farmers $36(83.7 \%)$, and traders 41 $(87.2 \%)$ had a positive attitude and this was statistically significant, $\mathrm{p}=0.001$ (Table 5). 


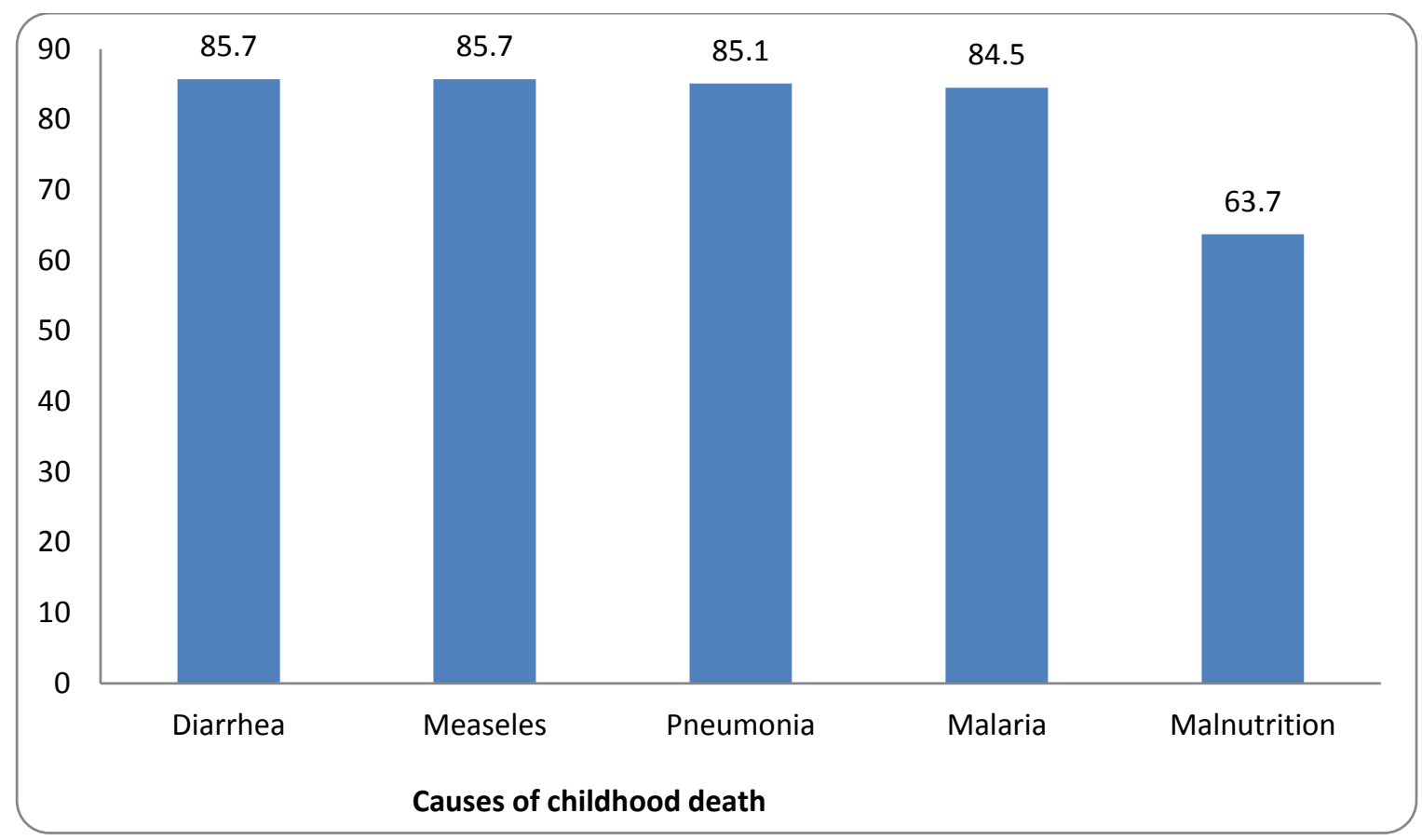

Figure 1: Respondents' knowledge of causes of childhood deaths

Table 2: Respondents' knowledge of risk factors influencing childhood mortality

\begin{tabular}{lcc}
\hline Risk factor & $\begin{array}{c}\text { Frequency } \\
\text { (n= 170) }\end{array}$ & Percent \\
\hline Maternal factors & 132 & 78.1 \\
Poor health seeking behaviour & 128 & 75.7 \\
Lack of education & 112 & 66.3 \\
Poverty & 89 & 52.7 \\
Lack of child proper spacing & 69 & 40.8 \\
Lack of family planning & 62 & 36.7 \\
Young age of mother & & \\
Child factors & 124 & 73.4 \\
Lack of breastfeeding & 123 & 72.8 \\
Not sleeping under mosquito nets & 116 & 68.6 \\
Poor hand washing & 102 & 60.4 \\
Lack of immunization & 66 & 39.1 \\
Low birth weight & 33 & 19.5 \\
Male sex & & \\
Household/community factors & 157 & 92.9 \\
Unhygienic water source & 142 & 84.0 \\
Poor sanitation & 133 & 78.7 \\
Poverty & 54 & 32.0 \\
Residence in rural areas & 43 & 25.4 \\
Large family size & & \\
& 17 & 10.0 \\
Overall Knowledge Score & 142 & 83.5 \\
Good & & \\
Fair & & \\
Poor & & \\
\hline
\end{tabular}


Table 3: Relationship between respondents' socio-demographic characteristics and knowledge score

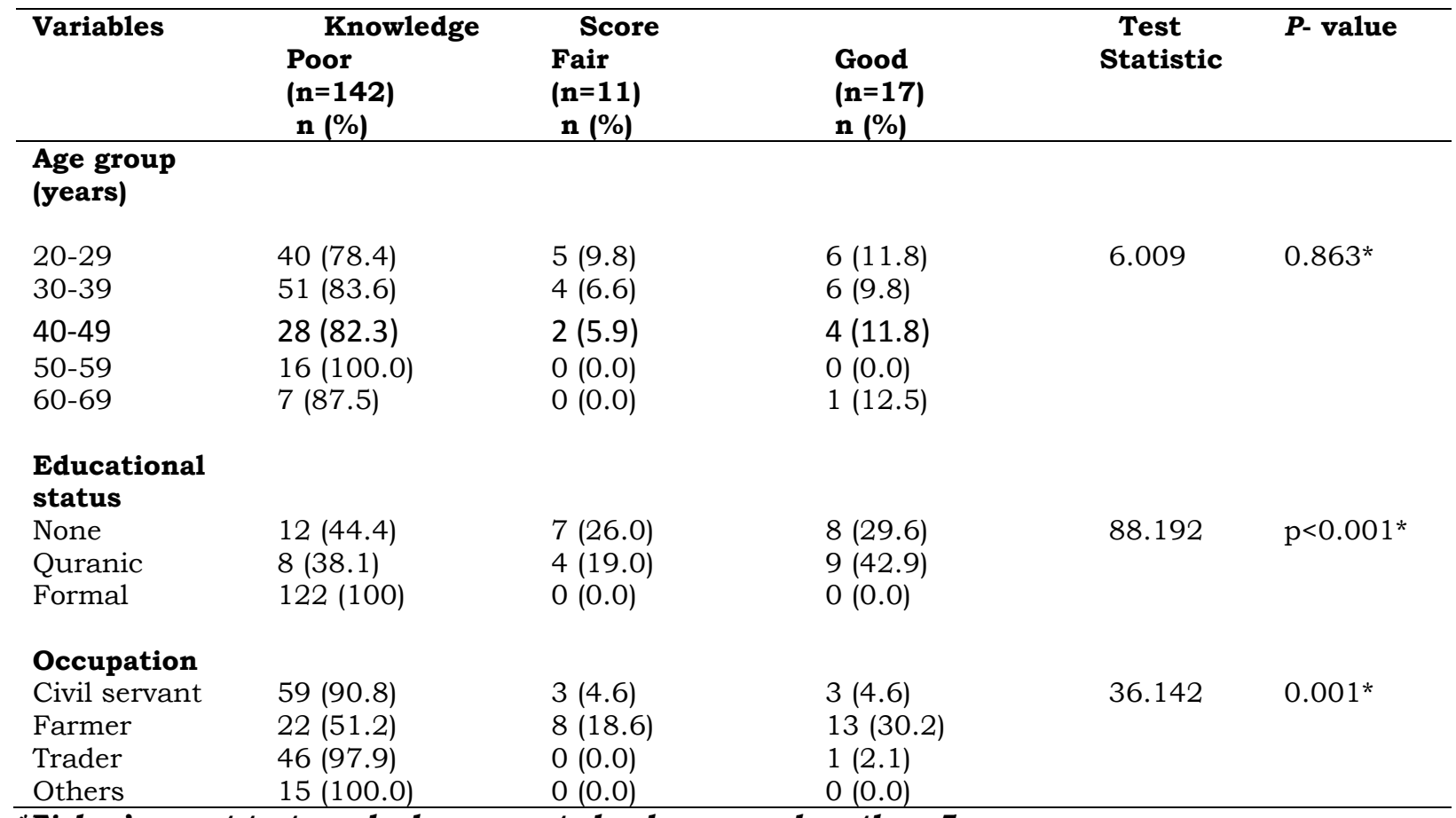

*Fisher's exact test used when expected values were less than 5

Table 4. Respondents' attitude towards prevention of childhood mortality

\begin{tabular}{llll} 
& & \multicolumn{2}{c}{ Responses } \\
\cline { 2 - 5 } Variable & $\begin{array}{l}\text { Agree } \\
\text { n (\%) }\end{array}$ & $\begin{array}{l}\text { Neutral } \\
\text { n (\%) }\end{array}$ & $\begin{array}{l}\text { Disagree } \\
\text { n (\%) }\end{array}$ \\
\hline & & & \\
Childhood deaths are preventable & $85(50.0)$ & $54(31.8)$ & $31(18.2)$ \\
Childhood immunization can reduce/prevent childhood deaths & $99(58.2)$ & $33(19.4)$ & $38(22.4)$ \\
Family planning can help in reducing childhood deaths & $50(29.4)$ & $25(14.7)$ & $95(55.9)$ \\
Children should always sleep under insecticide treated nets & $121(71.1)$ & $45(26.5)$ & $4(2.4)$ \\
Breastfeeding provides nutrition and protects children from diseases & $99(58.2)$ & $30(17.7)$ & $41(24.1)$ \\
Female education can help in reducing the burden of childhood deaths & $142(83.5)$ & $19(11.2)$ & $9(5.3)$ \\
\hline $\mathbf{( n = 1 7 0 )}$ & & &
\end{tabular}

\section{DISCUSSION}

Childhood mortality remains a major global issue with a disproportionate occurrence in sub-Saharan Africa where about half of the deaths occur. ${ }^{5}$ In Nigeria, regional disparities occur with the north-west region where this study was carried out having the highest proportion of childhood deaths. About two-third of the respondents had lost a child before the age of five years. This is not surprising due to the fact that child mortality rates in north west Nigeria (117 per 1,000$)$ supersede the national average (69 per1,000) and this trend has been maintained for the past 10 years. ${ }^{3}$ The causes of death were mainly preventable with pneumonia, measles, diarrhoea, malaria and malnutrition being the most common. 
Table 5: Relationship between respondents' socio-demographic characteristics and attitude score

\begin{tabular}{|c|c|c|c|c|}
\hline Variable & $\begin{array}{l}\text { Attitude } \\
\text { Negative } \\
\text { (n=29) } \\
\text { n (\%) }\end{array}$ & $\begin{array}{l}\text { Score } \\
\text { Positive } \\
(\mathrm{n}=141) \\
\mathrm{n}(\%)\end{array}$ & Test statistic & $P$-value \\
\hline \multicolumn{5}{|c|}{ Age group (years) } \\
\hline $20-29$ & $12(23.5)$ & 39 (76.5) & 5.027 & $0.413^{*}$ \\
\hline $30-39$ & $10(16.4)$ & 51 (83.6) & & \\
\hline $40-49$ & $6(17.6)$ & $28(82.4)$ & & \\
\hline $50-59$ & $0(0.0)$ & $16(100.0)$ & & \\
\hline $60-69$ & $1(12.5)$ & 7 (87.5) & & \\
\hline \multicolumn{5}{|l|}{$\begin{array}{l}\text { Educational } \\
\text { status }\end{array}$} \\
\hline None & $16(59.3)$ & $11(40.7)$ & 88.931 & $\mathrm{p}<0.001^{*}$ \\
\hline Quranic & 13 (61.9) & $8(38.1)$ & & \\
\hline Formal & $0(0.0)$ & $122(100.0)$ & & \\
\hline \multicolumn{5}{|l|}{ Occupation } \\
\hline Civil servant & $12(18.5)$ & 53 (81.5) & 53.169 & 0.001 \\
\hline Farmer & 7 (16.3) & 36 (83.7) & & \\
\hline Trader & $6(12.8)$ & 41 (87.2) & & \\
\hline Others & $4(26.7)$ & $11(73.3)$ & & \\
\hline
\end{tabular}

Only about a third of the respondents in this study correctly identified the age of the mother as a risk factor for childhood mortality. This is similar to a study carried out in Ogun State, South-west Nigeria where just $26.6 \%$ of the respondents knew that pregnancy at a younger age below 15 years often results in adverse outcomes for both the child and the mother. ${ }^{19}$ Culturally, both study communities embrace early marriage, hence the similarity in the findings which showed a very low proportion viewed young age of mother as a risk factor for childhood mortality. In view of the fact that the risk for infant mortality is greater with adolescent mothers, 20 the respondents' poor knowledge poses a threat to the efforts made to reduce childhood mortality. Adolescent mothers are more likely to have babies that are low birth weight or born prematurely which increases the risk of mortality. 20
Large family size, an important risk factor, was identified by only $25.4 \%$ of respondents. This factor works in tandem with the fact that an unacceptably high proportion of Nigerians live well below the poverty line to increase the rate of childhood deaths. This effect is more marked in the study setting which is a notably resource poor area. A study carried out in Ganmo, a semi-urban settlement in Kwara State north-central Nigeria concluded that the majority of the respondents who happen to be muslims have preference for large family sizes. ${ }^{21}$ These studies were carried out in areas where Islam is the predominant religion; together with the cultural beliefs, however the reasons for the respondents to view large families in a favourable light could not be explored within the scope of this study. Reduced birth interval, especially less than two years is associated with an increased risk of under-five mortality. ${ }^{22}$ Studies have 
shown that large family size has a negative effect on the nutritional status of underfives which in turn is one of the greatest causes of under-five mortality. ${ }^{23}$ A study carried out in Plateau State showed that high parity leading to large family size was associated with an increased risk of childhood mortality. ${ }^{24}$ Larger family size is also associated with poor health seeking behaviour which in turn has an impact on childhood mortality. ${ }^{25}$

Lack of breastfeeding and immunization were however seen by a large proportion of the respondents $(73.4 \%$ and $60.4 \%$, respectively) as important determinants of childhood mortality. This finding is corroborated by a study in Plateau State where majority of the respondents had good knowledge of the benefits of immunization and were willing to support it. ${ }^{24}$ The similarity of the findings is likely due to the fact that awareness and uptake of immunization is higher in urban areas than in rural areas. Breastfeeding and immunization are essential components of child survival strategies which were put in place to lower childhood mortality rates. As a result, adequate knowledge and consequently practice would have an effect in combating under-five morbidity and mortality. ${ }^{26}$

Attitudes towards childhood mortality risk factors were positive in most of the respondents. Majority believed that female educations, as well as poverty alleviation are important strategies towards reducing the burden of childhood mortality. Good attitude can help achieve positive behavioural changes with proper interventions and behavioural change communication. This resonates with the findings of a qualitative study in Borno State where respondents were of the opinion that the government needs to expand poverty alleviation programs, and invest in girl-child education, in an effort to improve maternal and consequently child health. ${ }^{27}$

More than two-thirds of the respondents agreed that immunizations protect children against diseases and can help in reduction and prevention of childhood deaths. In comparison, a study in Ekiti State also found positive attitudinal disposition of men towards immunization, as $78.8 \%$ of the men believed that children are protected from certain diseases when immunized and men have a role to play in childhood immunization. ${ }^{13}$ This is in contrast to a study carried out in Kano State where despite a high knowledge of immunization, most of the men had negative attitudes towards immunization. This is because most of the respondents who are rural dwellers, feel that "the government has neglected important sectors of development but constantly disturbs them with vaccination on regular basis".28 This disparity in attitudes is likely due to the fact that majority of the respondents in this study had a higher level of education which in turn will lead to better uptake of available health services than those with poor educational status. The knowledge, personal and social skills provided through education can better equip individuals to 
access and use information and services to maintain and improve their own and their family's health. ${ }^{29}$

This study had some limitations that warrant mention. The data analysed in this study were derived from self-reported information and are likely affected by social desirability and recall biases. During the data collection, the researcher and his assistants took appropriate steps to minimize social desirability bias, including private one-on-one interviews without the presence of a third party, assurance of confidentiality, voluntary participation, and informed consent. In the same vain, married men in the community who have married at least a year prior to survey were included in the study to minimize recall bias.

Conclusion: The study showed that although knowledge of the major direct causes of childhood deaths was high, knowledge of the risk factors was generally poor. Attitude towards prevention of childhood mortality were mostly favourable. The State Government through the Ministry of Health should embark on enlightenment campaigns via media outlets and hospitals to enlighten the public on the risk factors that predispose to childhood mortality.

\section{REFERENCES}

1. Alkema L, Chao F, You D, Pedersen J, Sawyer CC. National, regional, and global sex ratios of infant, child, and under-five mortality and identification of countries with outlying ratios: A systematic assessment. Lancet Glob Heal 2014; 2(9): 521-530.
DOI:https://doi.org/10.1016/S2214109X(14)70280-3. [Cited 22nd July 2019] Available from:

https://linkinghub.elsevier.com/retrieve Lpii/S2214109X14702803

2. World Health Organization: Children: reducing mortality 2020. [cited 6 Sept,2020]. Available from: https://www.who.int/news-room/factsheets/detail/ children-reducingmortality

3. National Population Commission (NPC) [Nigeria] and ICF. Nigeria Demographic and Health Survey 2018 Key indicators Report. Abuja. Nigeria, and Rockville, Maryland, USA: NPC and ICF. 2019. 748

4. Onyearugha CA, Okoronkwo NC, Onyemachi PE. Mortality pattern in children aged 1-60 months at a tertiary healthcare institution, Southeast Nigeria. Ann Medical Health Sci. Res 2020; 10: 907-911

5. United Nations Inter-Agency Group for Child Mortality Estimation (UNIGME), Report 2020. UNICEF for every child. UNICEF data: monitoring the situation of children and women, Under-five mortality Sept, 2020. [Internet]. [cited 20 Aug, 2020]. Available from: https://data.unicef.org/topic/childsurvival/under-five-mortality/

6. Kayode GA, Adekanmbi VT, Uthman OA. Risk factors and a predictive model for under-five mortality in Nigeria: evidence from Nigeria Demographic and Health Survey. BMC Pregnancy Childbirth 2012; 12(10): 11-22. [cited 6th Sept,2020] Available from:

http://www.biomedcentral.com/14712393/12/10

7. Adanikin AI, Padmadas SS, McGrath N. Recurrent child mortality risks and parity transition in Nigeria. Reprod Health 2019; 16(1): 1-10. DOI:10.1186/s12978-0190733-6 [cited $7^{\text {th }}$ Sept, 2020] Available from:

https://link.springer.com/articles/10.11 86/s12978-019-0733-6

8. Mkandawire E, Hendriks SL. A qualitative analysis of men's involvement in maternal and child health as a policy intervention in rural Central Malawi. BMC Pregnancy Childbirth 2018; 18(1): 37. DOI:10.1186/s12884-018-1669-5 [cited $7^{\text {th }}$ Sept, 2020]. Available from: https://bmcpregnancychildbirth.biomed central.com/articles/10.1186/ s12884$\underline{018}$ 
9. Yahaya S, Okonofua F, Ntoimo L, Udenigwe O, Bishwajit G. Men's perception of barriers to women's use and access of skilled pregnancy care in rural Nigeria: A qualitative study. Reprod Health 2019; 16(1): 86.

DOI:10.1186/s12978-019-0752-3. [cited $7^{\text {th }}$ Sept, 2020]. Available from: https://reproductive-healthjournal.biomedcentral.com/articles / 10.1 186/s12978-019-0752-3

10. Nasreen HE, Leppard M, Al Mamun M, Billah M, Mistry SK, Rahman M, et al. Men's knowledge and awareness of maternal, neonatal and child health care in rural Bangladesh: a comparative cross sectional study. Reprod Health 2012; 9(1): 18. DOI: 10.1186/1742-4755-9-18 [cited 13 th Jul, 2019]. Available from: http:/ / reproductive-healthjournal.biomedcentral.com/articles/10.1

11. Mashoto KO, Malebo HM, Msisiri E, Peter E. Prevalence, one week incidence and knowledge on causes of diarrhea: household survey of under-fives and adults in Mkuranga district, Tanzania. BMC Public Health. 2014; 14(1): 98. DOI: 10.1186/1471-2458-14-9855. Available from:

http://www.ncbi.nlm.nih.gov/pubmed/2 5241912

12. Aniebue PN, Aniebue UU, Adimora GN. Knowledge and beliefs about exclusive breastfeeding among rural Nigerian men in Enugu, Southeast Nigeria. Breastfeed Med 2010; 5(4): 169-171.

DOI.org/10.1089/bfm.2009.0082 [cited 14th Sept, 2019] Available from: http://www.ncbi.nlm.nih.gov/pubmed/2 0658896

13. Agboola SM, Busari OA, Segun-Agboola BT, Olajide TJ, Shabi OM, Elegbede OT. Knowledge, attitude, perceptions of adult males towards childhood immunizations in southwest Nigeria. Am J Heal Res 2015; 3(1): 8-11. DOI:

10.11648/j.ajhr.20150301.122.

Available from:

https://pdfs.semanticscholar.org/30c1/ eaf24b3485ffceef067603c5

6d1d5f61b7e7.pdf

14. National Bureau of Statistics (NBS) and United Nations Children's Fund (UNICEF). 2018 Multiple Indicator Cluster Survey 2016-17, Survey Findings Report. Nigeria Federal Ministry of Health Abuja, Nigeria: National Bureau of Statistics (2018) Main Report, Abuja Nigeria. 2018.
15. Singh, AS, Masuku, MB. Sampling techniques \& determination of sample size in Applied Statistics Research: An overview. International Journal of Economics, Commerce and Management United Kingdom 2014; 2(11): 1-22. [Cited 6th May, 2019] Available from ijecm.co.uk/wp

16. Oluseye OM, Kehinde DR, Akingbade O, Ogunlade O L, Onyebigwa OO, Oluwatosin OA. Knowledge and utilization of referral system among health care workers in selected Primary Health Care centres in Oyo State, Nigeria. Journal of Community Medicine and Primary Health Care, 2019; 31(1): 67-75

17. USAID. Basic Maternal and Newborn Care: Basic Antenatal Care Course Notebook for Trainers [Internet]. 2011 [cited 2019 Nov 16]. Available from: www.mnh.jhpiego.org

18. Tegegne TK, Sisay MM. Menstrual hygiene management and school absenteeism among female adolescent students in Northeast Ethiopia. BMC Public Health.

2014; 14(1): 1118. Doi:10.1186/14712458-14-1118.

19. Akinbode AO, Akinbode OO, EniOlunrola T. Knowledge and attitude of mothers on risk factors influencing pregancy outcomes in Abeokuta South LGA, Ogun State. . European Scientific Journal. 2015; 11(11): 313-324.

20. Neal S, Channon AA, Chintsanya J. The impact of young maternal age at birth on neonatal mortality: Evidence from 45 low and middle income countries. PLoS One 2018; 13(5): 1-16.

doi.org/10.1371/journal.pone.0195731 [cited 2020 Aug 24] Available from: /pmc/articles/PMC5965834/?report=ab $\underline{\text { stract }}$

21. Odu OO, IJadunola KT, Parakoy D.B. Reproductive behaviour and determinants of fertility among men in a semi-urban Nigerian community. Journal of Community Medicine and Primary Health Care 2005; 17(1): 13-19

22. Gebretsadik S, Gabreyohannes E. Determinants of under-five mortality in high mortality regions of Ethiopia: An analysis of the 2011 Ethiopia Demographic and Health Survey Data. Int J Popul Res. 2016; 2016:1-7. https://doi.org/10.1155/2016/ $\underline{1602761}$ 
23. Baranowska-Rataj A, Barclay K, Kolk $M$. The effect of number of siblings on adult mortality: Evidence from Swedish registers for cohorts born between 1938 and 1972. Journal Population Studies 2017; 71(1): 43-63

Doi: $10.1080 / 00324728.2016 .1260755$

24. Envuladu E, Osagie I, Mohammed A, Collins J, Okoh E, Zoakah A. Maternal practices affecting under-five mortality in a suburban area of Jos, North-Central Nigeria. Br J Med Med Res. 2015; 7(7): 598-603.

25. Latunji OO, Akinyemi OO. Factors influencing health-seeking behaviour among civil servants in Ibadan, Nigeria. Ann Ibadan Postgrad Med 2018; 16(1): 52-60. [cited Sep 6, 2020] Available from: http://www.ncbi.nlm.nih.gov/pubm ed/30254559

26. Victory EI, Effiong JH, Udoh IA, Bassey US, Emem A. Knowledge and practice of child survival strategies among mothers attending postnatal clinic in Itu, a sub-urban area of South Nigeria. Int $\mathrm{J}$ Heal Sci Res 2020; 10: 1-8. Available from: www.ijhsr.org

27. Abbas AI, Bukar HM. Perspectives on gendered education development in Nigeria: Evidence from Yobe State, Nigeria, 2009-2015. J Adv Res Soc Behav Sci. 2017; 9(1): 57-74.

28. Ahmad I, Yunusa I, Wudil A, Gidado $Z$, Sharif A, Kabara H. Knowledge, attitude, perception and beliefs of parents/care givers about polio immunization. International Journal of Public Health Research. 2015; 3(5): 104-109.

29. Higgins C, Lavin T. Health Impacts of Education a review. The Institute of Public Health in Ireland, 2008: 1-36 [cited 6th Sept, 2020]. https://www.publichealth.ie /files/file/Health\%20Impacts\%20of \%20Education.pdf. 